\title{
O papel da problematização freireana em aulas de ciências/física: articulações entre a abordagem temática freireana e o ensino de ciências por investigação
}

\author{
The role of the Freirean problematization in science/physics \\ lessons: articulations between the Freirean thematic approach \\ and science teaching by inquiry
}

Ana Paula Solino ${ }^{1}$. Simoni Tormölhen Gehlen ${ }^{2}$

\begin{abstract}
Resumo: O trabalho investiga o papel da problematização freireana no contexto de uma proposta didático-pedagógica baseada nas relações entre a Abordagem Temática Freireana e o Ensino de Ciências por Investigação (ENCI). Foram desenvolvidas atividades de Ciências/Física numa escola pública na cidade de Itabuna/BA, com alunos dos Anos Iniciais, tendo como foco a temática "Rio Cachoeira: que água é essa?", que emergiu de um problema local vivenciado pela comunidade escolar. A obtenção dos dados deu-se a partir de gravações em áudio, diário e produções dos alunos, os quais foram analisados por meio da Análise Textual Discursiva. Destaca-se que a problematização freireana pode contribuir para estruturar os problemas das atividades de Ciências/Física do ENCI, além de possibilitar que os alunos reflitam sobre situações problemáticas da sua realidade, ao mesmo tempo em que exercem uma postura investigativa perante os problemas práticos da ciência.
\end{abstract}

Palavras-chave: Problematização. Paulo Freire. Investigação. Ensino de ciências.

\begin{abstract}
This paper investigates the role of Freirean problematization in the context of a pedagogical-didactic proposal based on the relations between Freirean Thematic Approach and Science Teaching by Inquiry (ENCI). We developed Sciences/Physics activities at a public school in the city of Itabuna, Bahia, Brazil, with students from Initial Years from the Elementary School, focused on the theme: "Rio Cachoeira: what water is this?", which emerged from a local problem experienced by the school community. Data were collected through audio recordings, teacher's diary and student productions and analyzed by Discursive Textual Analysis. It is noteworthy that the Freirean problematization contributed to structure to the Science/Physics activities from ENCI, and to enable the students to reflect on the problematic situations from their own reality, while exercised an investigative attitude towards the practical problems of science.
\end{abstract}

Keywords: Problematization. Paulo Freire. Inquiry. Science teaching.

\footnotetext{
${ }^{1}$ Faculdade de Educação (FE), Universidade de São Paulo (USP), Avenida da Universidade, 308, Cidade Universitária, CEP 05508-040, São Paulo, SP, Brasil. Email: < ana.solino@gmail.com>

${ }^{2}$ Programa de Pós-Graduação em Educação em Ciências, Universidade Estadual de Santa Cruz (UESC), Ilhéus, BA, Brasil.
} 


\section{Introdução}

Os estudos sobre a importância do problema no ensino de Ciências têm ocupado um espaço relevante na área de didática das ciências. Parece haver um consenso entre os pesquisadores sobre a necessidade de propor problemas para auxiliar na aprendizagem dos estudantes. Esse consenso pode ser evidenciado em diversos trabalhos, tais como: Azevedo (2004); Barbosa-Lima e Carvalho (2002); Carvalho (2011, 2013); Carvalho et al. (1998); Delizoicov (2005); Francisco Jr., Ferreira e Hartwig (2008) e Gil-Pérez et al. (1992).

A literatura sobre este tema tem sido bastante ampla e complexa devido à abrangência de referenciais teóricos adotados pelos pesquisadores, os quais defendem propósitos e métodos de ensino variados. Destaca-se, também, a polissemia do termo problema, sobretudo em relação ao seu papel nas questões de ensino-aprendizagem. A pesquisa realizada por Gehlen e Delizoicov (2011) revela que o papel do problema abordado em alguns estudos em ensino de Ciências pode ser configurado de duas formas: seguindo a perspectiva da abordagem conceitual, em que o problema se constitui como um artifício que organiza as atividades para abordar conceitos; assim como pode seguir a perspectiva da abordagem temática, em que os conceitos são subordinados a um tema, o qual representa um problema.

Atualmente, alguns pesquisadores têm se preocupado em investigar e ressignificar o papel do problema no decorrer do processo educativo (DELIZOICOV, 2005; GEHLEN, 2009). Delizoicov (2005), por exemplo, chama a atenção para o fato de que os problemas a serem utilizados em sala de aula devem transpor a ideia de uma lista de exercícios repetitivos e descontextualizados retirados do livro didático. Para este autor, os problemas precisam ser significativos para os estudantes e estruturadores de todo o processo didático-pedagógico, com $\mathrm{o}$ intuito de favorecerem a aprendizagem dos alunos.

Neste sentido, Delizoicov, Angotti e Pernambuco (2002) têm organizado atividades de Ciências tendo como referência a Abordagem Temática Freireana, em que é explorada a problematização de situações reais que emergem de contradições sociais vivenciadas pelos alunos. Diversos trabalhos foram desenvolvidos com base nesta proposta de ensino, a exemplo de Silva (2004), que propôs a temática "Falta de Água em Americanópolis/SP" para os alunos dos anos finais do Ensino Fundamental. Segundo o autor, esse tema representava uma contradição social, uma vez que a comunidade escolar acreditava que a escassez de água nessa cidade era uma fatalidade, e não um problema social. Outro exemplo é apresentado por Lindemann (2010), a qual abordou a problemática relativa à Agricultura num assentamento Sem Terra no município de Fraiburgo/ SC, em que foram identificadas situações-limite envolvidas nas práticas dos agricultores, como: a produção de carvão vegetal, a produção de fumo e o uso intensivo de agrotóxicos.

Além desta abordagem de ensino, existem propostas na perspectiva do Ensino de Ciências por Investigação (ENCI) que têm sido frequentemente utilizadas por pesquisadores que procuram trabalhar o ensino de Ciências/Física nos Anos Iniciais do Ensino Fundamental, a exemplo de: Campos et al. (2012); Carvalho et al. (1998); Rosa, Rosa e Pecatti (2007); Sasseron (2008); Schroeder (2007), entre outros. Em geral, estes trabalhos envolvem atividades investigativas em que os alunos necessitam resolver uma situação-problema relacionada a um determinado fenômeno científico, por meio de algumas etapas e/ou ações que caracterizam o fazer ciência (SASSERON, 2008).

Tomando como objetos de estudos a perspectiva da Abordagem Temática Freireana e o Ensino de Ciências por Investigação (ENCI), há indicativos de que ambas as propostas, 
além de contemplarem a utilização de problemas em aulas de Ciências, os utilizam como ponto de partida para a construção do conhecimento científico dos alunos. Todavia, a Abordagem Temática Freireana e o ENCI se diferenciam quanto às concepções teóricas adotadas, bem como, quanto à natureza do problema a ser trabalhado em sala de aula (SOLINO; GEHLEN, 2014).

Em meio aos distanciamentos entre tais abordagens de ensino, entende-se que pode haver possibilidades de articulações entre elas, no que concerne, sobretudo, ao papel desempenhado pelo problema no contexto das atividades de ciências, aspecto já apontado no estudo teórico realizado por Solino e Gehlen (2014). Sendo assim, pretende-se discutir, com base em informações empíricas, se essas articulações são procedentes, sobretudo em relação às possíveis contribuições da problematização freireana em aulas de Ciências baseadas nas relações entre a Abordagem Temática Freireana e o Ensino de Ciências por Investigação ${ }^{3}$ (ENCI). Parte-se do pressuposto de que a inserção da problematização freireana numa proposta baseada nas relações entre ambas as perspectivas pode trazer contribuições epistemológicas para o contexto de sala de aula.

\section{O papel do problema na Abordagem Temática Freireana e o Ensino de Ciências por Investigação (ENCI) e suas relações}

A Abordagem Temática Freireana, proposta por Delizoicov, Angotti e Pernambuco (2002), é uma perspectiva de reorganização curricular, na qual os conteúdos das disciplinas escolares são subordinados a uma temática. Esta abordagem encontra-se fundamentada nas ideias de educação progressista de Freire e Snyders, tendo como um dos principais focos o diálogo e a problematização de situações significativas vivenciadas pelos estudantes. Sua organização se diferencia da lógica tradicional de estruturação do currículo em que os conteúdos são pontos de partida para direcionar o ato educativo. $\mathrm{Na}$ abordagem freireana, os temas que emergem de contradições sociais/existenciais vivenciadas pelos estudantes/comunidade são considerados pontos de partida para estruturar todo o processo didático-pedagógico (DELIZOICOV; ANGOTTI; PERNAMBUCO, 2002).

Para selecionar as temáticas organizativas do currículo escolar, é necessário realizar o processo de Investigação Temática proposto por Freire (1987), e sistematizado por Delizoicov (1991) em cinco etapas: (1) Levantamento Preliminar: mapeamento das principais situações significativas envolvidas na realidade local dos alunos e comunidade; (2) Codificação: análise e escolha das situações problemáticas vivenciadas pelos estudantes e comunidade; (3) Descodificação: diálogos estabelecidos com os sujeitos envolvidos no processo, a fim de obter os Temas Geradores; (4) Redução Temática: seleção dos conteúdos/conceitos necessários para compreensão do tema e planejamento das atividades seguindo os Momentos Pedagógicos e os Conceitos Unificadores; (5) Desenvolvimento em Sala de Aula: implementação da proposta em sala de aula.

Estudos têm investigado essa abordagem de ensino no contexto da Educação Básica, a exemplo de: Furlan et al. (2011), Lindemann (2010), Pernambuco (2001), Silva (2004), Souza et al. (2014), Stuani (2010), e Torres (2010). Nestes trabalhos, é evidente que o critério de escolha

\footnotetext{
${ }^{3}$ As discussões sobre a perspectiva do Ensino de Ciências por Investigação (ENCI) foram respaldadas, em grande parte, nas ideias de Carvalho et al. (1998) e Schiel e Orlandi (2009).
} 
do tema/problema abordado em sala de aula baseia-se em uma contradição social. Para Freire (1987), a contradição social está relacionada com as situações-limite, as quais podem ser entendidas como obstáculos que dificultam aos sujeitos reconhecerem e superarem as problemáticas locais que vivenciam. Um dos objetivos da perspectiva freireana é problematizar tais situações para os estudantes, levando-os a sentirem necessidade de buscar e apreender novos conhecimentos que podem ajudá-los no enfrentamento de problemas significativos e reais.

Por outro lado, o Ensino de Ciências por Investigação (ENCI) também é uma perspectiva que tem privilegiado o uso de problemas em sala de aula, a qual tem encontrado respaldo nas ideias de Piaget e Bachelard (CARVALHO, 2011). Historicamente, as atividades investigativas surgiram por volta do século XX, por influência das ideias do educador e filósofo Dewey, e, com o decorrer do tempo, essa perspectiva sofreu diversas mudanças quanto aos seus objetivos, métodos e fundamentos teóricos. Em decorrência dessas modificações, diferentes nomenclaturas foram sendo utilizadas para defini-la, como: ensino por descoberta, resolução de problemas, projetos de aprendizagem, ensino por investigação.

Para Zômpero e Laburú (2011, p. 73), existem alguns aspectos que caracterizam as atividades investigativas, como "o desenvolvimento de habilidades cognitivas nos alunos, a realização de procedimentos como elaboração de hipóteses, anotação e análise de dados e o desenvolvimento da capacidade de argumentação". De modo semelhante, Irias et al. (2007) destacam que o ENCI é uma metodologia de ensino ${ }^{4}$ que tem como objetivo levar os alunos a construírem seus conhecimentos, desenvolvendo habilidades de observação, argumentação e de análise. Os autores ainda destacam que a proposta do ENCI visa alfabetizar cientificamente os estudantes logo nos primeiros anos do Ensino Fundamental, uma vez que as crianças têm a oportunidade de formular e testar hipóteses, procurando relacionar suas observações com outros fenômenos.

Diversos grupos de educadores e pesquisadores brasileiros têm realizado iniciativas de implementação dessa proposta de ensino para o contexto escolar, a exemplo do "Projeto ABC

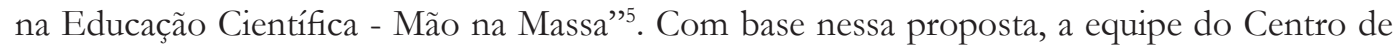
Divulgação Científica e Cultural (CDCC) da Universidade de São Paulo (USP), campus de São Carlos, elaborou algumas atividades investigativas no livro "Ensino de Ciências por Investigação" (SCHIEL; ORLANDI, 2009), com o intuito de subsidiar o planejamento e as ações do professor em sala de aula. Outro grupo importante, vinculado à Faculdade de Educação da USP, é o Laboratório de Pesquisa e Ensino de Física (LaPEF). Este grupo tem realizado propostas de ensino por investigação para o contexto escolar, e ainda tem divulgado um significativo volume de pesquisas que buscam analisar as contribuições dessa abordagem de ensino para a aprendizagem dos alunos e a formação do professor. O grupo também organizou um livro, denominado "Ciências no ensino fundamental: o conhecimento físico" (CARVALHO et al., 1998), contendo diversas atividades investigativas de física para alunos dos anos iniciais. As atividades presentes nesse livro estão estruturadas a partir das seguintes etapas e/ou ações investigativas:

\footnotetext{
${ }^{4}$ Há pesquisadores que denominam o ENCI de metodologia ou estratégia didática. No âmbito desse estudo, compreende-se o ENCI como uma perspectiva de ensino, uma vez que é fundamentado em aspectos epistemológicos e pedagógicos.

${ }^{5}$ Para mais informações sobre o projeto consultar: <http://www.cienciamao.usp.br/tudo/pagina.php?projeto=/ maonamassa>. Acesso em: 16 ago. 2015.
} 
[...] o professor propõe o problema; agindo sobre os objetos para ver como eles reagem; agindo sobre os objetos para obter o efeito desejado; tomando consciência de como foi produzido o efeito desejado; dando explicações causais; escrevendo e desenhando; relacionando a atividade e cotidiano. (CARVALHO et al., 1998, p. 40)

Nesta proposta, as atividades são organizadas com foco em problemas e envolvem etapas da investigação científica, tais como: proposição de um problema em torno de um objeto ou fenômeno natural; formulação de hipóteses; realização da atividade experimental; discussões das observações e conclusões; e o registro de toda a atividade. De acordo com Sasseron (2008), estas etapas têm como objetivo proporcionar, ao aluno, o conhecimento da cultura científica, a fim de que eles possam utilizá-lo para resolver os problemas do dia a dia e tomar decisões que envolvam a ciência, tecnologia, sociedade e meio ambiente. Cabe ressaltar que as atividades investigativas não se reduzem àquelas experimentais, podendo incluir atividades de natureza teórica (CARVALHO, 2013).

Solino e Gehlen (2014), ao estudarem as possibilidades de articulações pedagógicas e epistemológicas entre a proposta do Ensino de Ciências por Investigação e a Abordagem Temática Freireana, analisaram, dentre outros aspectos, o papel do problema. As autoras ressaltam que tanto o ENCI quanto a Abordagem Temática Freireana apresentam aspectos que envolvem as dimensões epistemológicas e pedagógicas do problema. Ambas as propostas destacam o problema como elemento fundamental em suas atividades de ensino, embora as abordagens apresentem particularidades entre si.

No ENCI, o problema encontra-se diretamente relacionado aos fenômenos científicos e à natureza da ciência (CARVALHO et al., 1998). O problema envolvido na atividade possui relações com o objeto de conhecimento, que, neste caso, são os conceitos científicos. O problema está vinculado ao propósito da atividade, que é levar os alunos à construção dos conceitos científicos e a apropriação do fazer científico. Tal característica parece apresentar aspectos relacionados à dimensão epistemológica do problema, uma vez que Carvalho (2013) destaca o seu papel como gênese na construção dos conhecimentos, ao fundamentar-se em Piaget e Bachelard. Nessa perspectiva de ensino, o critério de escolha dos problemas para estruturar as atividades é conceitual, pois os temas de ciências são transformados em problemas didáticos para serem, então, investigados e resolvidos pelos estudantes (CARVALHO et al., 1998). Ainda que, em geral, as atividades baseadas no ENCI tenham proposto problemas mais próximos da dimensão conceitual, alguns trabalhos têm apresentado atividades que são estruturadas a partir de temáticas relacionadas aos aspectos socioambientais, como é o caso do tema Navegação e Meio Ambiente, discutido por Sasseron (2008), ou propostas vinculadas aos blocos temáticos dos parâmetros curriculares nacionais (PCN) (BRASIL, 1997), como Meio Ambiente, Ser Humano e Saúde e Recursos Tecnológicos, exploradas por Nascimento (2012). Há indicativos de que essas atividades estão próximas da estruturação curricular baseada na Abordagem Temática ${ }^{6}$, não

\footnotetext{
${ }^{6}$ Strieder et al. (2011) apontam que, embora a Abordagem Temática tenha sido proposta por Delizoicov, Angotti e Pernambuco (2002), baseada em Freire, ela não se centra, exclusivamente, na perspectiva freireana, podendo abarcar várias outras abordagens de ensino, a exemplo das propostas CTS e Situação de Estudo.
} 
especificamente numa perspectiva freireana, uma vez que os temas são essenciais para organizar toda a programação curricular.

$\mathrm{Na}$ perspectiva freireana, a natureza do termo problema está relacionada a um determinado momento histórico, fruto das desigualdades sociais que representam contradições vivenciadas pelos estudantes. Isto é, o problema, sintetizado no Tema Gerador, é que vai ser o ponto de partida para a abordagem do conhecimento científico pelo professor. Nesse sentido, a dimensão epistemológica do problema perpassa não só o processo de obtenção do tema, mas, também, a organização de toda programação curricular, sobretudo a seleção dos conteúdos e conceitos (DELIZOICOV, 1991; GEHLEN, 2009).

Quanto à dimensãopedagógica, a Abordagem Temática Freireana e o ENCI se aproximam no sentido de que o problema cumpre a função de mediar as relações entre os sujeitos e o objeto de conhecimento. Além dessa função mediadora, o problema na perspectiva do Ensino por Investigação estrutura o corpo de cada atividade de ensino a partir de problemas conceituais. Estes se configuram como ponto de partida para organizar as atividades, tornando-se um artifício didático pedagógico. Ou seja, as perguntas ou desafios feitos pelo professor numa aula investigativa são, em geral, decorrentes de problemas que envolvem temas de ciências, os quais podem ter relações com o cotidiano dos estudantes. Para resolvê-los é necessário não apenas o entendimento dos conceitos científicos, mas, também, as compreensões sobre a natureza da ciência e as relações entre Ciência-Tecnologia-Sociedade-Ambiente (NASCIMENTO, 2012; SASSERON, 2008). Por outro lado, na Abordagem Temática Freireana, os problemas possuem uma ênfase na dimensão sócio-política, pois as problematizações realizadas pelo professor são oriundas das contradições locais vivenciadas pelos estudantes (DELIZOICOV; ANGOTTI; PERNAMBUCO, 2002). É importante ressaltar que os questionamentos feitos pelo professor em torno do problema também requerem do aluno a conceituação científica para compreendê-los, porém, os conceitos não se constituem como ponto de partida na organização curricular.

Apesar de ambas as perspectivas apresentarem compreensões distintas quanto à natureza e a função do problema, Solino e Gehlen (2014) sinalizam que elas podem se articular durante o desenvolvimento em sala de aula, a partir da organização das atividades com base nos Três Momentos Pedagógicos propostos por Delizoicov, Angotti e Pernambuco (2002), quais sejam: Problematização Inicial, Organização do Conhecimento e Aplicação do Conhecimento. Nesta relação, durante a Problematização Inicial, apresentam-se, aos alunos, questionamentos relacionados a uma problemática com ênfase social, envolvida na temática geradora, com o intuito de apreender as ideias, experiências e saberes dos estudantes. Na Organiz̧ação do Conhecimento, o professor poderá utilizar os problemas com ênfase conceitual presentes nas atividades investigativas para trabalhar com os alunos. As etapas investigativas de levantamento de hipóteses, manipulação do objeto, constatação e socialização dos resultados podem ser exploradas esse momento. Por último, na Aplicação do Conhecimento, ao retornar novamente à Problematização Inicial envolvida no tema, o professor poderá trabalhar a última etapa investigativa proposta por Carvalho et al. (1998) e Schiel e Orlandi (2009), que é a elaboração de relatórios escritos e/ou desenhados pelos alunos. Além disso, o professor poderá também problematizar novas questões. 


\section{Encaminhamentos metodológicos}

Essa pesquisa foi organizada em quatro fases: (a) seleção de um tema; (b) seleção dos conteúdos e elaboração dos planejamentos das aulas baseada no tema; (c) desenvolvimento das atividades em sala de aula, e (d) análise da implementação. Ao se realizar a primeira etapa do processo de Investigação Temática (FREIRE, 1987), denominada de levantamento preliminar, foi constatado um problema que representava uma contradição social vivenciada pelos moradores da cidade de Itabuna/BA. Tal contradição estava relacionada à problemática da poluição das águas do Rio Cachoeira, o qual banha grande parte deste município. A identificação deste problema resultou em um tema para ser trabalhado em sala de aula, denominado: Rio Cachoeira: que água é essa? Para implementá-lo no contexto da disciplina de Ciências, foram selecionados, durante o processo de Redução Temática (FREIRE, 1987), alguns conteúdos/conceitos relevantes de Física, Química, Biologia e Educação Ambiental, assim como foram elaboradas dez aulas, três delas contendo atividades experimentais investigativas, baseadas no ENCI: Flutua ou Afunda? (SCHIEL; ORLANDI, 2009); Problema do Barquinho e Problema da Pressão (CARVALHO et al., 1998). As dez aulas foram desenvolvidas numa turma do $5^{\circ}$ ano do Ensino Fundamental de uma escola municipal da cidade de Itabuna/BA, envolvendo alunos entre 9 e 10 anos de idade. O desenvolvimento dessas atividades ocorreu no período de maio a junho de 2012, sendo implementado pela pesquisadora (professora da turma na ocasião), com apoio do Grupo de Estudos sobre Abordagem Temática no Ensino de Ciências (GEATEC), vinculado à Universidade Estadual de Santa Cruz (UESC).

Os dados foram obtidos por meio do Diário do Professor (PORLÁN; MARTÍN, 1999), registrados durante as aulas pela professora-pesquisadora e integrantes do grupo de estudo; gravações em áudio das falas dos alunos no decorrer das aulas, e produções escritas dos estudantes. As informações foram analisadas pela Análise Textual Discursiva (MORAES; GALIAZZI, 2011), conforme as seguintes etapas: unitarização: momento em que as falas mais significativas dos alunos foram fragmentadas, resultando em unidades de significados; categorização: organização das unidades de significados a partir da categoria - problematização; metatexto: comunicação dos resultados em forma de análise. Para organizar as informações, os sujeitos foram identificados da seguinte maneira: para as falas dos alunos extraídas dos áudios, tem-se: A1, A2, An...; para as falas dos alunos extraídas do diário: D1, D2, Dn..., e para as produções dos alunos: P1, P2, Pn...

\section{Análise da problematização freireana nas aulas de Ciências/Física}

Em linhas gerais, a estrutura das três atividades investigativas de Ciências/Física escolhidas para compor o planejamento das aulas baseadas no tema Rio Cachoeira: que água é essa? seguiu as relações estabelecidas entre a Abordagem Temática Freireana e o ENCI, aspecto discutido anteriormente. Isto é, no âmbito desta temática, as atividades foram reorganizadas tendo como base a dinâmica dos Três Momentos Pedagógicos, conforme síntese apresentada no Quadro 1. Tais atividades investigativas foram iniciadas durante o segundo momento pedagógico - Organização do Conhecimento-, que consistiu em apresentar um problema experimental para os alunos com o intuito de resolvê-lo por meio de: ações investigativas de levantamento de hipóteses, constatação, socialização de resultados e registro da atividade (CARVALHO et al., 1998; SCHIEL; ORLANDI, 2009). 
Vale lembrar que a escolha do tema e o planejamento das atividades didático-pedagógicas deram-se por meio de algumas etapas do processo de Investigação Temática Freireana, explicitadas na seção anterior. Além disso, o tema selecionado neste estudo representa uma contradição social vivenciada pelos estudantes, no contexto de uma situação-limite (FREIRE, 1987; SILVA, 2004), uma vez que o problema da poluição das águas do Rio Cachoeira da cidade de Itabuna/BA, muitas vezes, é visto pela comunidade como uma fatalidade, favorecendo uma visão acrítica dos alunos.

No Quadro 1, observa-se que as Problematizações Iniciais antecedem o desenvolvimento das atividades experimentais investigativas (terceira coluna), balizadas pelos pressupostos do ENCI. É nesse momento inicial que as perguntas direcionadas pelo professor deverão ser organizadas com base nas relações homem-mundo (FREIRE, 1987), ou seja, nas relações entre o sujeito do conhecimento, que, nesse caso, são os alunos do $5^{\mathrm{a}}$ ano, e o objeto de conhecimento, que abrange a problemática relacionada à poluição das águas do rio, além dos conceitos científicos explorados no segundo momento pedagógico.

Ao analisar o papel da problematização presente nas três aulas 4, 5 e 7 de Ciências/Física, explicitadas no Quadro 1, compreende-se que a mesma está vinculada a um problema de dimensão sócio-política. Isto é, um problema historicamente situado num determinado contexto, tendo significado para os alunos refletirem e buscarem novos conhecimentos. Essas aulas foram planejadas de modo a contemplar situações significativas, diretamente relacionadas com a temática Rio Cachoeira: que água é essa?

Na dinâmica dos Momentos Pedagógicos, a Problematização Inicial constitui a primeira etapa a ser trabalhada em sala de aula. Nesse momento, as situações significativas envolvidas na temática necessitam ser problematizadas pelo professor, a fim de que este apreenda os conhecimentos prévios dos alunos, aguçando as curiosidades deles sobre a temática em estudo (DELIZOICOV, 2005). Sobre este aspecto, Ricardo (2011) salienta que, ao se proporem situações problematizadoras em aulas de ciências, é necessário que os estudantes se afastem criticamente dos seus conhecimentos vulgares, a fim de que sintam necessidade de buscar novos conhecimentos. O autor também destaca que o ponto de partida e de chegada para estruturar as atividades deve ser a realidade dos alunos, sendo a problematização um caminho para analisar criticamente o contexto real dos estudantes.

O propósito dessas três aulas foi problematizar algumas situações importantes sobre a flutuação dos lixos e das embarcações encontrados no Rio Cachoeira, e o modo como essa água é distribuída para as casas e a escola, além de desenvolver, nos alunos, uma postura reflexiva sobre os problemas sociais da sua realidade. Dentre as problematizações trabalhadas nas aulas, destacam-se:

Por que alguns desses lixos encontrados no Rio Cachoeira flutuam e outros afundam? Quais lixos afundam e quais flutuam? (Aula 4);

Por que as canoas, os barcos e navios que são feitos de material "pesado" conseguem boiar no Rio Cachoeira? O que faz com que eles flutuem ou afundem? (Aula 5);

Como essa água tratada, do Rio Cachoeira, chega até as casas, escolas, fábricas e indústrias? Você já observou em que local fica a caixa d'água de sua casa? Por que ela fica no alto? (Aula 7). 
Quadro 1. Organização das atividades investigativas com base nos Três Momentos Pedagógicos.

\begin{tabular}{|c|c|c|c|}
\hline \multicolumn{4}{|c|}{ TEMA: Rio Cachoeira: que água é essa? } \\
\hline Aula & Problematização inicial & Organização do conhecimento & $\begin{array}{l}\text { Aplicação do } \\
\text { conhecimento }\end{array}$ \\
\hline 4 & $\begin{array}{l}\text { Apresentar para os } \\
\text { alunos vários objetos } \\
\text { (lixos) possivelmente } \\
\text { encontrados no Rio } \\
\text { Cachoeira e problematizar } \\
\text { as seguintes questões: } \\
\text { Por que alguns desses } \\
\text { lixos encontrados no } \\
\text { Rio Cachoeira flutuam e } \\
\text { outros afundam? Quais } \\
\text { afundam e quais flutuam? }\end{array}$ & $\begin{array}{l}\text { Conceito trabalhado: Flutuação, Massa. } \\
\text { Atividade experimental investigativa: "Flutua } \\
\text { ou Afunda" (SCHIEL; ORLANDI, 2009, p. } \\
\text { 77), seguindo algumas etapas do ENCI: } \\
\text { (a) Problema: Quais objetos afundam e } \\
\text { quais flutuam?; (b) Manipulação dos objetos } \\
\text { na água; (c) Levantamento de hipóteses; d) } \\
\text { Verificação das hipóteses; (d) Socialização dos } \\
\text { resultados e sistematização do professor. }\end{array}$ & $\begin{array}{l}\text { Retomada da } \\
\text { problematização } \\
\text { inicial; } \\
\text { Confecção } \\
\text { do relatório } \\
\text { escrito/ } \\
\text { desenhado. }\end{array}$ \\
\hline 5 & $\begin{array}{l}\text { Ao analisar a imagem } \\
\text { do pescador no Rio } \\
\text { Cachoeira, respondam: } \\
\text { Por que as canoas, os } \\
\text { barcos e navios, que } \\
\text { são feitos de material } \\
\text { 'pesado', conseguem boiar } \\
\text { no Rio Cachoeira? O que } \\
\text { faz com que eles flutuem } \\
\text { ou afundem? }\end{array}$ & $\begin{array}{l}\text { Conceito trabalhado: Volume e Densidade. } \\
\text { Atividade experimental investigativa: } \\
\text { "Problema do Barquinho" (CARVALHO et } \\
\text { al., 1998, p. 78), seguindo algumas etapas do } \\
\text { ENCI: } \\
\text { (a) Problema: Como será que a gente faz } \\
\text { para construir um barquinho que na água } \\
\text { consiga carregar o maior número de pecinhas } \\
\text { sem afundar?; (b) Manipulação dos objetos } \\
\text { na água; (c) Levantamento de hipóteses; d) } \\
\text { Verificação das hipóteses; (d) Socialização dos } \\
\text { resultados e sistematização do professor. }\end{array}$ & $\begin{array}{l}\text { Retomada da } \\
\text { problematização } \\
\text { inicial; } \\
\text { Confecção } \\
\text { do relatório } \\
\text { escrito/ } \\
\text { desenhado. }\end{array}$ \\
\hline 7 & $\begin{array}{l}\text { Problematizar com os } \\
\text { alunos a seguinte questão: } \\
\text { Como essa água tratada } \\
\text { chega até as casas, } \\
\text { fábricas, indústrias? Você } \\
\text { já observou em que local } \\
\text { fica a caixa de água da sua } \\
\text { casa? Por que ela fica no } \\
\text { alto? }\end{array}$ & $\begin{array}{l}\text { Conceito trabalhado: Pressão Hidrostática. } \\
\text { Atividade experimental investigativa: } \\
\text { "Problema da Pressão" (CARVALHO et al., } \\
\text { 1998), seguindo algumas etapas do ENCI: } \\
\text { (a) Problema: Vamos descobrir um jeito de } \\
\text { fazer o potinho ficar sempre cheio d'água. } \\
\text { Mas só podemos jogar água no tubo, tá legal?; } \\
\text { (b) Manipulação dos objetos na água; (c) } \\
\text { Levantamento de hipóteses; (d) Verificação } \\
\text { das hipóteses; (e) Socialização dos resultados e } \\
\text { sistematização do professor. }\end{array}$ & $\begin{array}{l}\text { Retomada da } \\
\text { problematização } \\
\text { inicial; } \\
\text { Confecção } \\
\text { do relatório } \\
\text { escrito/ } \\
\text { desenhado. }\end{array}$ \\
\hline
\end{tabular}

Fonte: Solino (2013, p. 134).

A partir desses questionamentos foi possível observar um expressivo engajamento dos alunos nas atividades, os quais tiveram a oportunidade de levantar hipóteses e de expor seus 
conhecimentos sobre o assunto. $\mathrm{Na}$ aula 4, por exemplo, para problematizar a questão dos lixos encontrados no rio da cidade a professora-pesquisadora distribuiu igualmente para grupos de alunos alguns materiais que simbolizavam possíveis lixos, tais como: palito de sorvete, pedaços de borrachas, copos descartáveis, pedaços de plásticos, restos de madeiras, papel, latinhas de refrigerante, entre outros. Para cada equipe foi dada uma bacia com água e os alunos deveriam testar as hipóteses que haviam discutido anteriormente com seus colegas. Antes de realizar tal atividade, a professora-pesquisadora problematizou a seguinte questão: "Diante desses materiais (lixos), que nós podemos encontrar lá no Rio Cachoeira, por que alguns deles podem flutuar ou afundar na água?”, grande parte dos alunos explicou que era devido à "leveza" dos lixos, isto é: “[o lixo flutua] por que é leve” (aluno A4).

Frente a esta resposta dada não apenas pelo aluno A4, mas por grande parte da turma, a professora-pesquisadora, na tentativa de explorar um pouco mais os saberes das crianças, aprofundou a problematização e obteve uma série de informações importantes que ajudaram no direcionamento da atividade. Foram selecionados fragmentos de falas que exemplificam o diálogo problematizador do primeiro momento pedagógico. Neste diálogo há a participação da professora-pesquisadora, dos alunos e um dos pesquisadores do GEATEC/UESC, denominado de pesquisador 1, de acordo com o Quadro 2.

Quadro 2. Fragmentos de falas significativas no contexto da aula 4.

\begin{tabular}{|l|l|}
\hline \multicolumn{1}{|c|}{ Fragmento 1: Unidades de significado } & \multicolumn{1}{c|}{ Sujeitos } \\
\hline Mas se o lixo é leve vai acontecer o que? & professora-pesquisadora \\
\hline Vai boiar. & alunos em coro respondem \\
\hline Vai boiar, porque é leve? E o quê mais? & professora-pesquisadora \\
\hline O pesado vai afundar! & alunos em coro respondem \\
\hline Ele desce pro fundo. & aluno A5 \\
\hline Me dê um exemplo de um lixo que afunda no Rio Cachoeira. & professora-pesquisadora \\
\hline O pneu! & aluno A4 \\
\hline$[\ldots]$ o pneu é leve ou pesado? & pesquisador 1 \\
\hline Pesado. & alunos em coro respondem \\
\hline E ele afunda? & pesquisador 1 \\
\hline Afunda. & aluno A4 \\
\hline Não afunda nada! & maioria dos alunos respondem \\
\hline E ele [pneu] é o que? Pesado, née? & pesquisador 1 \\
\hline É [...] & alunos em coro respondem \\
\hline [...] então, quais lixos no Rio Cachoeira podem flutuar? & professora-pesquisadora \\
\hline Madeira, rolo, garrafa [...] & alunos em coro respondem \\
\hline
\end{tabular}

Fonte: Solino (2013, p. 137). 
Durante a Problematização Inicial, recomenda-se que o professor organize as discussões em sala de aula, buscando diagnosticar os entendimentos dos alunos acerca da situação problematizada. A esse respeito, é possível constatar, no Quadro 2, que algumas crianças apresentam ideias confusas sobre a flutuabilidade dos corpos, em especial, sobre os objetos que possivelmente poderão afundar no rio, a exemplo da resposta explicitada pelo aluno A4, quando a professora -pesquisadora questionou: "Me dê um exemplo de um lixo que afunda no Rio Cachoeira" e o aluno A4 respondeu: "O pneu”. No diálogo explicitado no Quadro 2, verifica-se que a maioria dos alunos afirmou, imediatamente, que o pneu não afundava, refutando a ideia do aluno A4. Tal fato pode estar relacionado às experiências vivenciadas por eles, ao verem os pneus flutuando em alguns locais do Rio Cachoeira, sobretudo quando estes são utilizados no tratamento de despoluição ${ }^{7}$ do rio. Constata-se, aqui, que o problema em estudo atrelado à poluição do Rio Cachoeira permite aguçar as memórias, lembranças e experiências advindas da realidade dos educandos, aspecto também ressaltado por Lindemann (2010) ao afirmar que o estudo da realidade propicia a construção e reconstrução, em conjunto, dos cenários do contexto em que os alunos fazem parte. Muenchen (2010) também corrobora com esta ideia argumentando que a problematização pode possibilitar que os estudantes interpretem suas vidas não apenas passando por elas. Certamente, esse aspecto pode potencializar a construção do conhecimento dos estudantes.

Observa-se, portanto, que o diálogo entre a professora-pesquisadora e os alunos em torno dos lixos encontrados no Rio Cachoeira faz parte do contexto deles. Ou seja, os objetos (lixos) que estavam sendo manipulados pelas crianças para serem testados posteriormente sobre a bacia com água, tinham uma relação direta com o estudo da temática. Em se tratando de atividades experimentais, é importante que não seja explorada somente a ação dos alunos, mas, sim, a sua reflexão em torno da situação existencial problematizada (RICARDO, 2005).

Outro exemplo importante destaca-se na aula 5, quando a professora-pesquisadora problematiza uma imagem antiga do rio cachoeira que retrata alguns pescadores em seus barcos e canoas navegando sobre o rio. Após os alunos observarem a imagem, a professora-pesquisadora questiona-os: "Vocês estão vendo a foto antiga do Rio Cachoeira, não estão? [...] agora vocês vão tentar responder com os conhecimentos de vocês, por que será que esse barquinho consegue flutuar nessa água? O que será que acontece?”.

Após a leitura desta imagem, os alunos tiveram a oportunidade de discutir oralmente suas concepções e, em seguida, registraram, por escrito, suas ideias. Algumas destas respostas podem ser encontradas no Quadro 3.

\footnotetext{
${ }^{7}$ No Rio Cachoeira é possível encontrar alguns pneus amarrados em forma de rede sobre as águas, com o intuito de concentrar as plantas aguapés para ajudar a despoluir o rio, ao mesmo tempo em que impede a proliferação desses vegetais, preservando a vida dos peixes e protozoários. Esta foi uma ação do "Projeto SustentaCidade" implantado pela Empresa Municipal de Águas e Saneamento (EMASA) da cidade de Itabuna/BA, no ano de 2011.
} 
Quadro 3. Fragmentos de escritas significativas no contexto da aula 5.

\begin{tabular}{|l|c|}
\hline \multicolumn{1}{|c|}{ Fragmento 2: Unidades de significado } & Sujeitos \\
\hline O barco, navio ou canoa boia por causa da maré do rio ou mar. & Aluno P8 \\
\hline Eles boiam porque eles tem forma côncava, e eles afundam porque pode ter um furo. & Aluno P5 \\
\hline Á água faz. com que boie e pode ser um tipo de madeira especial. & Aluno P4 \\
\hline Por que os navios é tipo uma boia, por isso não afunda. & Aluno P7 \\
\hline $\begin{array}{l}{[. . .] \text { eles conseguem flutuar por causa que tem uns que são leves e são feitos de madeiras e tem outros }} \\
\text { que são pezados' e são feitos de comcreto. }\end{array}$ & Aluno P12 \\
\hline Eu acho que o barco flutua por que ele tem poca massa. & Aluno P9 \\
\hline
\end{tabular}

Fonte: Solino (2013, p. 138-139).

Nesse diálogo, é possível identificar respostas bem distintas dadas pelos alunos. Alguns buscaram explicar o problema da flutuação dos barcos no Rio Cachoeira sob o ponto de vista da influência das águas; outros abordam a forma e o tipo do material que compõem o barco, e outro faz relação com a massa. Compreende-se que as palavras "massa", "leve" e "pesado" escritas pelos alunos $\mathrm{P} 12 \mathrm{e} \mathrm{P} 9$ podem ter sido utilizadas por eles devido à aula 4, em que foram trabalhadas algumas noções sobre a flutuação de objetos (lixos). Isso quer dizer que a atividade experimental da aula anterior parece ter sido significativa para eles, em especial, para P9, que ampliou o seu vocabulário ao escrever uma nova palavra representativa de conceito científico.

Gehlen, Maldaner e Delizoicov (2012) ressaltam que a problematização na perspectiva freireana permite que os alunos utilizem não só os seus conhecimentos do senso comum, a exemplo da resposta do estudante P8, quando diz que: "o barco, navio ou canoa boia por causa da maré do rio on mar", mas, também, os saberes mais próximos da ciência, ainda que sejam apresentados pelas crianças de forma confusa, conforme é possível destacar no registro do aluno P9: "Eu acho que o barco flutua por que ele tem 'poca' massa".

Esse movimento das crianças de tentarem dar explicações científicas à situação significativa problematizada, já desde a primeira etapa do momento pedagógico, confirma o que Freire (2002) sempre ressaltou, que a educação dialógica-problematizadora permite diminuir o abismo entre os dois níveis de conhecimento: o senso comum e o científico. $O$ autor ainda acrescenta que a problematização não implica apenas a participação ativa dos estudantes, mas, também, do professor. É nessa relação com o outro que o conhecimento vai sendo problematizado e construído. A função do educador nessa relação dialógica não é apresentar, para os estudantes, a resposta pronta, acabada, mas, sim, "problematizar aos educandos o conteúdo que os mediatiza" (FREIRE, 2002, p. 81), conteúdo este, não desvinculado da sua realidade concreta.

Essa construção de argumentos escritos que foram trabalhados durante a problematização inicial parece ter sido uma estratégia importante para a professora constatar os diferentes pontos

\footnotetext{
${ }^{8}$ Optou-se por não corrigir as palavras grafadas pelos alunos em suas atividades escritas.
} 
de vistas dos alunos, além de poder ajudá-la a orientar os próximos passos da aula em relação ao aprofundamento da questão analisada. Sobre isso, Freire (1987) afirma que o professor precisa criar possibilidades para que os alunos sintam necessidade de se aprofundarem na situação, abrindo novos caminhos de compreensão e posicionamento crítico sobre o objeto analisado, fato este que caracteriza a curiosidade epistemológica (FREIRE, 2004). Algumas curiosidades podem ser pontuais por carência de informações, e outras podem ser reflexos de concepções amplas que requerem maior aprofundamento das problematizações (SILVA, 2004). Em relação a esta última, durante a Organização do Conhecimento, momento em que foram trabalhadas as atividades investigativas com base nos problemas de dimensão conceitual, foi observada, ainda no decorrer da aula 5, a curiosidade do aluno A17 em querer conhecer mais a respeito do tema em estudo, ao questionar: “Ô tia! Por que aquelas balsas conseguem carregar aqueles 'caixotes grandão' e não afunda?”. Para Freire (2002, p. 79), "quanto mais se pergunta, tanto mais sente que sua curiosidade em torno do objeto não se esgota". Tal questionamento parece ter possibilitado às outras crianças novas formas de compreenderem o problema, o que está em sintonia com Freire (2002) ao afirmar que é na relação com o outro que a situação problemática vai sendo desvelada e compreendida; assim como também apontam Carvalho et al. (1998), ao enfatizarem a importância da interação entre os alunos durante o processo de ensino-aprendizagem.

Nesse caso, a presença das embarcações encontradas no Rio Cachoeira foi importante para estabelecer relações com a realidade dos educandos, visto que o barquinho que está sendo problematizado é aquele que faz parte de uma contradição social, apresentada nas águas poluídas desse rio, e que é vivenciado por toda a população de Itabuna/BA. Ou seja, o barquinho problematizado em sala de aula está relacionado com o contexto dos alunos, uma vez que, neste rio, é possível encontrar canoas e balsas que são utilizadas por alguns pescadores, ainda que a poluição tenha tomado maiores proporções neste rio. Aqui é importante destacar que esse momento em sala de aula contribuiu com outra forma de validar o tema Rio Cachoeira: que água essa?, pois houve uma semelhança com a realização da $2^{\mathrm{a}}$ e $3^{\mathrm{a}}$ etapa da Investigação Temática (FREIRE, 1987), isto é: a codificação, momento em que foi apresentado, para os alunos, um código em forma de imagem sobre os barcos flutuando no Rio Cachoeira; e a descodificação, momento em que, à medida que os alunos dialogavam sobre os diferentes tipos de embarcações encontradas no Rio Cachoeira, sentiam necessidade de novos conhecimentos para um melhor entendimento da flutuação dos barcos nesse rio.

Já na aula 7, a intenção foi discutir de que maneira a água do Rio Cachoeira chega até as casas dos alunos. Para dar início à aula, foi problematizada a seguinte situação, iniciada no fragmento do Quadro 4.

As ideias apresentadas pelos alunos podem ser decorrentes tanto dos conhecimentos apreendidos na aula 6, na qual foi trabalhada a questão do tratamento da água do Rio Cachoeira, quanto das suas experiências do dia a dia. No que se refere ao fator das experiências trazidas para a sala de aula pelas crianças, é bem importante destacar, novamente, que as mesmas apresentam situações distintas que fazem parte da realidade delas, relatando uma outra forma de armazenamento de água em suas casas, a exemplo do uso de cisternas. Vale ressaltar que é o professor quem vai direcionar e organizar as discussões dos estudantes, não no sentido de dar respostas prontas, mas para questionar as interpretações assumidas pelos alunos (GEHLEN; MALDANER; DELIZOICOV, 2012). O docente precisa estar consciente desse papel deixando fluir as discussões sobre as necessidades e conflitos vivenciados pelos sujeitos (SILVA, 2004). 
Quadro 4. Fragmentos de falas significativas no contexto da aula 7.

\begin{tabular}{|l|l|}
\hline \multicolumn{1}{|c|}{ Fragmento 3: Unidade de significado } & \multicolumn{1}{c|}{ Sujeitos } \\
\hline $\begin{array}{l}\text { Vocês já observaram em que local fica a caixa d'água da sua casa? Por que ela tem que } \\
\text { ficar no alto? }\end{array}$ & professora-pesquisadora \\
\hline Eu já! & alunos em coro \\
\hline Tia, fica em cima das casas. & aluno A7 \\
\hline E por que será que elas têm que ficar em cima e não embaixo? & professora-pesquisadora \\
\hline É porque o cano [...] a água faz descer. & aluno A5 \\
\hline E aí, vocês concordam com o Felipe? & $\begin{array}{l}\text { professora-pesquisador } \\
\text { professora pesquisadora }\end{array}$ \\
\hline E aí Caio, o que você me diz? & aluno A9 \\
\hline A da minha casa fica no chão [...] lá em casa tem um negócio [...] uma cisterna [...] & professora-pesquisadora \\
\hline Tem cisterna? Pra quê essa cisterna? Pra que serve? & aluno A9 \\
\hline Pra pegar a água. &
\end{tabular}

Fonte: Solino (2013, p. 141).

Na Abordagem Temática Freireana, os Momentos Pedagógicos se intercalam um no outro a todo instante e não devem ser trabalhados de forma estanque (PERNAMBUCO, 2001). A problematização não precisa ser vista apenas como uma etapa em que aparece, exclusivamente, no primeiro momento pedagógico, mas, sim, retomada e reelaborada pelo professor ou pelo aluno a todo tempo. Um exemplo disso é o momento em que os alunos tentaram resolver o desafio proposto no problema da atividade do barquinho, na aula 5. As crianças elaboravam suas hipóteses utilizando apenas um único modelo de barco, que foi o de dobradura para flutuar na água com o maior número de pecinhas, conforme a fala explicitada pelo aluno A10: "tio disse que é pra fazer de outro tipo". Acrescenta o aluno A11: "A gente só sabe desse!'. Neste momento, foi preciso problematizar os tipos de embarcações que eles já conheciam ou que já viram flutuando sobre as águas do Rio Cachoeira. A presença deste problema relacionado à realidade permitiu que os conhecimentos das crianças fossem ampliados, sendo que uma grande parte da turma conseguiu lembrar de outros tipos de embarcações, a exemplo da canoa e da balsa, que, usualmente, são encontrados no Rio Cachoeira, como expressa a seguir o trecho da aula 5 (Quadro 5).

Mais uma vez, os fragmentos explicitados no Quadro 5 indicam que as problematizações não são perguntas distantes do contexto dos educandos, elas possuem um significado para eles e possibilitam aproximar as suas experiências e o conhecimento escolar. Convém ressaltar que a problematização freireana pode propiciar a transcendência de uma pergunta ao buscar soluções para os problemas da realidade do aluno. Isso ratifica a ideia de que toda problematização pode ser considerada uma pergunta, mas nem toda pergunta é uma problematização (GEHLEN et al., 2007). Na concepção freireana, para uma pergunta se tornar uma problematização, necessariamente precisa vincular-se a um tema que possui como núcleo um problema real, carregado de marcas reveladoras de contradições sociais vivenciadas pelos sujeitos. Lindemann (2010, p. 280) salienta que "não é qualquer tema que tem a potencialidade de fomentar uma apreensão da realidade, assim como não é de qualquer forma que se obtém e se trabalha em sala de aula". 
Quadro 5. Fragmentos de falas significativas no contexto da aula 5.

\begin{tabular}{|l|l|}
\hline \multicolumn{1}{|c|}{ Fragmento 4 - Unidades de significado } & \multicolumn{1}{c|}{ Sujeitos } \\
\hline$[\ldots .$.$] no Rio Cachoeira, a gente vê muito o quê?$ & professora-pesquisadora \\
\hline Canoa! & aluno A2 \\
\hline Como é que se faz uma canoa? & professora-pesquisadora \\
\hline É assim [aluno mostra com as mãos a forma do barco] & aluno A1 \\
\hline$[\ldots .$.$] tenta uma outra forma, só tem esse tipo?$ & professora-pesquisadora \\
\hline Tia, tem aquele também que é quadrado. & aluno A5 \\
\hline Qual é? & professora-pesquisadora \\
\hline Aquele tia, que o grupo dali tá fazendo. & aluno A5 \\
\hline A Balsa? & professora-pesquisadora \\
\hline É [...] & aluno A5 \\
\hline Tia nós fizemos uma canoa! & aluno A9 \\
\hline
\end{tabular}

Fonte: Solino (2013, p. 158).

Sendo assim, pretendeu-se mostrar, neste presente artigo, que a água do rio problematizada nas atividades não é uma simples água, comumente discutida nos livros didáticos de ciências. Essa água é marcada culturalmente por uma história que foi e continuará sendo escrita pelos sujeitos imersos nesse contexto. Essa água é uma realidade viva, construída e transformada pelos atores que dela fazem parte. E é em torno desse contexto histórico-cultural da realidade dos educandos que as problematizações devem ocorrer em sala de aula, favorecendo a atribuição de sentidos e significados na aprendizagem em ciências.

\section{Considerações finais}

Nesse estudo, procurou-se investigar as contribuições da problematização freireana no contexto de aulas de ciências baseadas nas relações entre a Abordagem Temática Freireana e o ENCI. Compreende-se que a problematização freireana contribui para estruturar todo o processo didático-pedagógico, sendo um elemento relevante para o critério de seleção de temáticas a serem trabalhadas na escola. Ou seja, ao se selecionar a situação problemática a partir de uma contradição social vivenciada pelos estudantes, as atividades didático-pedagógicas podem ser organizadas de modo a auxiliarem os alunos na compreensão do problema em estudo, sintetizado no tema Rio Cachoeira: que água é essa?

Ao se pensar o papel da problematização freireana nas relações que foram estabelecidas entre a Abordagem Temática Freireana e o ENCI, a partir dos Três Momentos Pedagógicos, há indicativos de que tais articulações trouxeram contribuições importantes para as duas perspectivas. Isto é, os problemas presentes nas atividades experimentais investigativas do ENCI, ao privilegiarem uma prática com ênfase na dimensão conceitual, podem potencializar o problema, durante a 
Organização do Conhecimento, no sentido de que esse Momento Pedagógico não explicita, de forma sistemática, um processo para a abordagem de conceitos científicos, conforme destacam Gehlen, Delizoicov e Maldaner (2012). Cabe ressaltar que esses autores também têm se preocupado com a sistematização da Organização do Conbecimento, propondo incorporar elementos da proposta de Situação de Estudo (2007) para esse segundo Momento Pedagógico, especialmente no que se refere à Significação Conceitual, baseada em Vygotsky. Assim, a contribuição dos problemas do ENCI para a Abordagem Temática Freireana está vinculada à dimensão pedagógica, uma vez que seu foco é levar os alunos ao entendimento dos conceitos científicos e à natureza da ciência. Quanto à problematização freireana, ao enfatizar uma prática com ênfase na dimensão sócio-política, pode contribuir para alavancar os problemas conceituais do ENCI, uma vez que os mesmos estão subordinados a uma temática problematizadora (FREIRE, 1987) de amplo significado para os alunos. Tal fato não exclui a importância dos problemas conceituais das atividades experimentais investigativas, mas, sim, amplia a sua significação, uma vez que estão atrelados a um problema real.

Defende-se, portanto, que é preciso considerar, nas atividades de sala de aula, um problema como critério de seleção e estruturação de todo o processo didático-pedagógico. Para Delizoicov (1991), ao se levar em consideração a qualidade do problema no âmbito das práticas educativas, o mesmo não deve ser reduzido apenas à sua função de mediar um determinado conceito, mas, também, é necessário cumprir a função de humanizar os sujeitos. Em síntese, a seleção de problemas a serem trabalhados em propostas que levem em consideração as articulações entre o ENCI e a Abordagem Temática Freireana necessita assumir uma dimensão epistemológica, não sendo apenas o ponto de partida na construção do conhecimento científico dos estudantes, mas, também, o ponto inicial para a construção do planejamento de toda sequência de atividades. Ao assumir esta função, os problemas conceituais, típicos das propostas do ENCI, podem tornar-se mais significativos para os alunos, uma vez que o processo investigativo estaria voltado para reflexões temáticas que envolvem problemas reais vivenciados pelos educandos.

\section{Agradecimentos}

Ana Paula Solino agradece ao apoio da Fundação de Amparo à Pesquisa do Estado da Bahia (FAPESB). 


\section{Referências}

AZEVEDO, M. C. P. S. Ensino por investigação: problematizando as atividades em sala de aula. In: CARVALHO, A. M. P. (Org.). Ensino de ciências: unindo a pesquisa e a prática. São Paulo: Thomson, 2004. p. 19-33.

BARBOSA-LIMA, M. C.; CARVALHO, A. M. P. Comprovando a necessidade dos problemas. In: ENCONTRO DE PESQUISA EM ENSINO DE FÍSICA, 8., 2002, Águas de Lindóia. Atas... São Paulo: Sociedade Brasileira de Física, 2002. v. 1. p. 1-15. Disponível em: <http://www.sbf1.sbfisica.org.br/eventos/epef/viii/PDFs/COCD4_2.pdf >. Acesso em: 12 ago. 2015.

BRASIL. Ministério da Educação e do Desporto. Secretaria de Educação Fundamental. Parâmetros curriculares nacionais: ciências naturais. Brasília, 1997.

CAMPOS, B. S. et al. Física para crianças: abordando conceitos físicos a partir de situações-problema. Revista Brasileira de Ensino de Física, São Paulo, v. 34, n. 1, p. 1402-1415, 2012.

CARVALHO, A. M. P. O ensino de ciências e a proposição de sequências de ensino investigativa. In: - (Org.). Ensino de ciências por investigação: condições para implementação em sala de aula. São Paulo: Cengage Learning, 2013. p. 1-20.

. Ensino e aprendizagem de ciências: referenciais teóricos e dados empíricos das sequências de ensino investigativo (SEI). In: LONGHINI, M. D. (Org). O uno e o diverso na educação. Uberlândia: EDUFU, 2011. p. 253-266.

CARVALHO, A. M. P. et al. Ciências no ensino fundamental: o conhecimento físico. São Paulo: Scipione, 1998.

DELIZOICOV, D. Conhecimento, tensões e transições. 1991. 214 f. Tese (Doutorado em Educação) - Faculdade de Educação, Universidade de São Paulo, São Paulo, 1991.

Problemas e problematizações. In: PIETROCOLA, M. (Org.). Ensino de

física: conteúdo, metodologia e epistemologia numa concepção integradora. 2. ed. rev. Florianópolis: UFSC, 2005. p. 125-150.

DELIZOICOV, D.; ANGOTTI, J. A.; PERNAMBUCO, M. M. Ensino de ciências: fundamentos e métodos. São Paulo: Cortez, 2002.

FRANCISCO JR., W. E.; FERREIRA, L. H.; HARTWIG, D. R. Experimentação problematizadora: fundamentos teóricos e práticos para a aplicação em salas de aula de ciências. Química Nova na Escola, São Paulo, n. 30, p. 34-41, nov. 2008.

FREIRE, P. Extensão ou comunicação? 12. ed. Rio de Janeiro: Paz e Terra, 2002.

Pedagogia da autonomia. 29. ed. Rio de Janeiro: Paz e Terra, 2004.

Pedagogia do oprimido. 17 ed. Rio de Janeiro: Paz e Terra, 1987. 
FURLAN, A. B. S. et al. Abordagem temática no currículo de ciências: a perspectiva éticocrítica na concepção de lixo como condição humana. In: ENCONTRO NACIONAL DE PESQUISA EM EDUCAÇÃO EM CIÊNCIAS, 8., 2011, Campinas. Atas... Disponível em: <http://www.nutes.ufrj.br/abrapec/viiienpec/resumos/R0412-1.pdf>. Acesso em: 12 ago. 2015.

GEHLEN, S. T. A função do problema no processo ensino-aprendizagem de ciências: contribuições de Freire e Vygotsky. 2009. 254 f. Tese (Doutorado em Educação Científica e Tecnológica) - Universidade Federal de Santa Catarina, Florianópolis, 2009.

GEHLEN, S. T.; DELIZOICOV, D. A função do problema na educação em ciências: estudos baseados na perspectiva vygotskyana. Revista Brasileira de Pesquisa em Educação em Ciências, São Paulo, v. 11, n. 3, p. 123-144, 2011.

GEHLEN, S. T.; MALDANER, O. A.; DELIZOICOV, D. Momentos pedagógicos e as etapas da situação de estudo: complementaridades e contribuições para a educação em ciências. Ciência \& Educação, Bauru, v. 18, n. 1, p. 1-22, 2012.

GEHLEN, S. T. et al. Um processo formativo na perspectiva freiriana: aprendizagens na formação dos formadores. In: ENCONTRO SOBRE INVESTIGAÇÃO NA ESCOLA, 7., 2007, Porto Alegre. Porto Alegre: EDIPUCRS, 2007. v. 7.

GIL-PERÉZ, D. et al. Questionando a didática de resolução de problemas: elaboração de um modelo alternativo. Caderno Catarinense de Ensino de Física, Florianópolis, v. 9, n. 1, p. 7-19, 1992.

IRIAS, C. V. et al. Uma experiência didática envolvendo a aplicação de atividade relacionada ao conhecimento físico na $2^{\mathrm{a}}$ série do ensino fundamental. In: ENCONTRO NACIONAL DE PESQUISA EM EDUCAÇÃO EM CIÊNCIAS, 6., 2007, Florianópolis. Atas... Florianópolis; UFSC, 2007.

LINDEMANN, R. H. Ensino de química em escolas do campo com proposta agroecológica: contribuições a partir da perspectiva freireana de educação. 2010. $339 \mathrm{f}$. Tese (Doutorado em Educação Científica e Tecnológica) - Universidade Federal de Santa Catarina, Florianópolis, 2010.

MALDANER, O. A. Situações de Estudo no Ensino Médio: nova compreensão de educação básica. In: NARDI, R. (org.). Pesquisa em Ensino de Ciências no Brasil: alguns recortes. Escrituras. São Paulo, 2007, p. 237-253.

MORAES, R.; GALIAZZI, M. C. Análise textual discursiva. 2. ed. rev. Ijuí: Ed. Unijuí, 2011.

MUENCHEN, C. A disseminação dos três momentos pedagógicos: um estudo sobre práticas docentes na região de Santa Maria, RS. 2010. 217 f. Tese (Doutorado em Educação Científica e Tecnológica) - Universidade Federal de Santa Catarina, Florianópolis, 2010. 
NASCIMENTO, V. B. Fundamentos e metodologia do ensino das ciências da natureza. Ilhéus: EDITUS, 2012. Disponível em: < http://nead.uesc.br/arquivos/ pedagogia/ciencia-natureza/modulo-ciencia.pdf > . Acesso em: 11 ago. 2015.

PERNAMBUCO, M. M. A. Significações e realidade: conhecimento. In: PONTUSCHKA, N. N. (Org). Ousadia no diálogo. 3. ed. São Paulo: Loyola, 2001. p. 67-92.

PORLÁN, R.; MARTÍN, J. El diario como instrumento para detectar problemas y hacer explícitas las concepciones. In: EL DIARIO del profesor: un recurso para la investigación en el aula. 7. ed. Sevilla: Diada, 1999. p. 18-42.

RICARDO, E. C. Competências, interdisciplinaridade e contextualização: dos parâmetros curriculares a uma compreensão para o ensino das ciências. 2005. 257 f. Tese (Doutorado em Educação Científica e Tecnológica) - Universidade Federal de Santa Catarina, Florianópolis, 2005.

. Problematização e contextualização no ensino de física. In: CARVALHO, A. M. P.

(Org.). Ensino de física. São Paulo: Cengage Learning, 2011. p. 37-52.

ROSA, C. W; ROSA, A. B.; PECATTI, C. Atividades experimentais nas séries iniciais: relato de uma investigação. Revista Electrónica de Enseñanza de las Ciencias, Vigo, v. 6, n. 2, p. 263-274, 2007.

SASSERON, L. H. Alfabetização científica no ensino fundamental: estrutura e indicadores deste processo em sala de aula. 2008. 180 f. Tese (Doutorado em Ensino de Ciências e Matemática) - Faculdade de Educação, Universidade de São Paulo, São Paulo, 2008.

SCHIEL, D.; ORLANDI, A. S. (Org.). Ensino de ciências por investigação. São Paulo: USP, Centro de Divulgação Científica e Cultural, 2009. Disponível em: <http:/ /www.cdcc. usp.br/maomassa/livros_ensinodeciencias.html>. Acesso em: 11 ago. 2015.

SCHROEDER, C. A importância da física nas quatro primeiras séries do ensino fundamental. Revista Brasileira de Ensino de Física, São Paulo, v. 29, n. 1, p. 89-94, 2007.

SILVA, A. F. G. A construção do currículo na perspectiva popular crítica: das falas significativas às práticas contextualizadas. 2004. 539 f. Tese (Doutorado em Educação) Pontifícia Universidade Católica de São Paulo, São Paulo, 2004.

SOLINO, A. P. Abordagem temática freireana e o ensino de ciências por investigação: contribuições para o ensino de ciências/física nos anos iniciais. 2013. Dissertação (Mestrado em Educação Científica e Formação de Professores) - Universidade Estadual do Sudoeste da Bahia, Jequié, 2013.

SOLINO, A. P.; GEHLEN, S. T. Abordagem temática freireana e o ensino de ciências por investigação: possíveis relações epistemológicas e pedagógicas. Investigações em Ensino de Ciências, Porto Alegre, v. 19, n. 1, p. 141-162, 2014. 
SOUZA; P. S. et al. Investigação temática no contexto do ensino de ciências: relações entre a abordagem temática freireana e a práxis curricular via tema gerador. Alexandria, Florianópolis, v. 7, n. 2, p. 155-177, 2014.

STRIEDER, R. S. et al. Abordagem de temas na pesquisa em educação em ciências: pressupostos teórico-metodológicos. In: ENCONTRO NACIONAL DE PESQUISA EM EDUCAÇÃO EM CIÊNCIAS, 8., 2001, Campinas. Atas... Campinas: Unicamp, 2011.

STUANI, G. M. A construção curricular popular crítica no ensino de ciências naturais e suas implicações na prática docente. 2010. 194 f. Dissertação (Mestrado em Educação Científica e Tecnológica) - Universidade Federal de Santa Catarina, Florianópolis, 2010.

TORRES, J. R. Educação ambiental crítico-transformadora e abordagem temática freireana. 2010. 456 f. Tese (Doutorado em Educação Científica e Tecnológica) Universidade Federal de Santa Catarina, Florianópolis, 2010.

ZÔMPERO, A. F.; LABURÚ, C. E. Atividades investigativas no ensino de ciências: aspectos históricos e diferentes abordagens. Ensaio, Belo Horizonte, v. 13, n. 3, p. 67-80, 2011.

\section{Nota das autoras}

Este artigo é derivado da dissertação de mestrado de Solino (2013). Partes dessa dissertação também foram publicadas em outros veículos, conforme referências abaixo:

SOLINO, A. P.; GEHLEN, S. T. A conceituação científica nas relações entre a abordagem temática freireana e o ensino de ciências por investigação. Alexandria: revista de educação em ciência e tecnologia, Florianópolis, v. 7, n. 1, p. 75-101, 2014.

. A contextualização na abordagem temática freireana e no ensino de ciências por investigação. In: ENCONTRO NACIONAL DE PESQUISA EM EDUCAÇÃO EM CIÊNCIAS, 9.,2013, Águas de Lindóia. Atas... São Paulo: ENPEC, 2013.

SOLINO, A. P.; SOUSA, P.; GEHLEN, S. T. A problematização freireana no contexto do ensino de ciências por investigação: contribuições para o ensino de física nos anos iniciais. In: SIMPÓSIO NACIONAL DE ENSINO DE FÍSICA, 20., 2013, São Paulo. Atas... São Paulo: USP, 2013.

Artigo recebido em 27/06/14. Aceito em 27/03/15. 